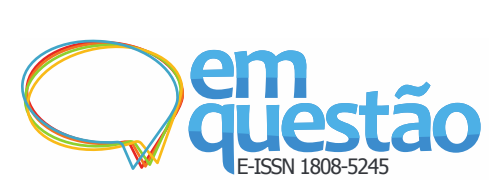

\title{
O Museu do Balseiro de Itá como patrimônio cultural de Santa Catarina
}

\author{
Ana Maria Dalla Zen \\ Doutora; Universidade Federal do Rio Grande do Sul, Porto Alegre, RS, Brasil; \\ azen@ufrgs.br \\ Lilian Santos da Silva Fontanari \\ Mestranda; Universidade Federal do Rio Grande do Sul, Porto Alegre, RS, Brasil; \\ lilian.ms.rs@gmail.com
}

Resumo: O objetivo deste trabalho é refletir sobre os sentidos e usos associados à preservação da prática dos balseiros que atuaram na década de 1920 em Itá, Santa Catarina, cujos saberes e fazeres vêm sendo (re)afirmados pelo Museu do Balseiro e de como o turismo local tem sido trabalhado no campo do patrimônio cultural. Apesar dos impactos da ação madeireira no meio ambiente, esse ofício se constitui em patrimônio cultural da região, pela produção de artefatos, meios de transporte e ferramentas de trabalho, fundamentado teoricamente na Museologia Social, Nova Museologia e Educação Para o Patrimônio. A metodologia inclui pesquisa documental de roteiro turístico e cultural que citam o museu, desenvolvidos pela Secretaria de Turismo, bem como de um projeto escolar, como referência para montagem de uma réplica de balsa, feita por alunos da Escola Municipal Valentim Bernardi. Analisa o impacto do turismo na patrimonialização do ofício do balseiro e os resultados da experiência como ação de educação para o patrimônio, a partir de relatos da coordenadora do projeto e alunos participantes, reunidos no momento de seu reencontro com a obra exposta no Museu. Discute as relações entre patrimônio cultural, Turismo e Educação para o Patrimônio, a fim de compreender o lugar que cultura e patrimônio ocupam em uma cidade turisticamente explorada. Problematiza as ações turísticas focadas nos espaços culturais, de recuperação e de preservação do patrimônio cultural dos balseiros na rede de ensino, e como estas têm sido negociadas e associadas à história local. Conclui que o turismo em Itá tem objetivos meramente econômicos e que desconhece a experiência de patrimonialização do ofício de balseiro como estratégia de recuperação de memórias e de educação para o patrimônio, por meio da apropriação de elementos da cultura do colonizador.

Palavras-chave: Museologia Social. Patrimônio cultural. Ação educativa em Museus. Museu do Balseiro de Itá. Turismo. 


\section{Introdução}

O município de Itá, em Santa Catarina, tornou-se conhecido por ter sido um centro de extração das araucárias de suas florestas, durante a década de 1920, quando de lá partiam balseiros, assim chamados os trabalhadores que desciam o rio Uruguai rumo ao sul do Brasil e da Argentina transportando em forma de balsas imensas quantidades de madeira extraída da Mata Atlântica. Mais recentemente, na década de 1980, a região voltou a ser noticiada porque a cidade foi alagada, para construção de uma hidrelétrica. Portanto, em sua História aparecem lado a lado a memória de uma atividade extrativista que provocou forte impacto ao ambiente natural, e um processo de desterritorialização, que forçou a recriação da cidade em outro espaço. Hoje, a prefeitura municipal transformou a região num polo turístico que se afirma como sustentável, mas que não considera o patrimônio cultural constituído pelo forte desejo de memória que nasceu entre os moradores, voltado à valorização da história da cidade que foi coberta pelas águas, consubstanciado na criação de seis museus na cidade, entre os quais o Museu do Balseiro.

$\mathrm{O}$ interesse em interpretar a relação entre turismo e memória na perspectiva do campo do patrimônio cultural resultou na elaboração de uma pesquisa junto ao Programa de Pós-Graduação em Museologia e Patrimônio (PPGMUSPA/UFRGS), tendo como referência o Museu do Balseiro. A investigação, que se constituirá numa dissertação de mestrado, estuda especificamente as representações que vem sendo feitas no Museu do Balseiro sobre as memórias e histórias de vida das mulheres dos balseiros. Vinculado a ela, este artigo discutirá como a atividade turística ignora as ações que vêm sendo realizadas pela comunidade no sentido de recuperar a história dos balseiros e torná-la elemento do patrimônio cultural da região. O recorte aqui apresentado focaliza o processo de construção de um modelo de balsa numa escola local, dentro de um projeto de ação educativa e cultural proposto por uma professora, na perspectiva da educação para o patrimônio, concebido na disciplina de turismo e sustentabilidade. 


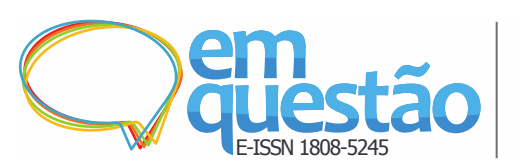

Fundamentada pela Museologia Social, Nova Museologia e Educação para o Patrimônio, a investigação vem revelando que, apesar dos impactos da ação madeireira no meio ambiente, o ofício é reconhecido pela comunidade como seu patrimônio cultural, pela produção de artefatos, meios de transporte e ferramentas de trabalho. O projeto, denominado Itá: ontem, hoje e amanhã, foi planejado e executado por um grupo de professores da Escola Valentim Bernardi, com o objetivo de refletir sobre o processo de criação e desenvolvimento local e aproximar as crianças de suas próprias histórias.

Para reforçar a importância das pessoas que construíram uma etapa da história itaense, um grupo de antigos balseiros orientou uma turma de alunos do quarto ano do Ensino Fundamental para a construção da maquete de uma balsa. A atividade gerou novas parcerias entre o museu e a escola, aproximou jovens e idosos, motivou a reconstrução de memórias e contribuiu para a afirmação de identidades. A participação da educadora da escola responsável pelo projeto no Encontro dos Balseiros, evento anual do Museu que reúne os antigos balseiros para uma rememoração de suas vidas, em 2017, com a produção de um documentário, teve grande repercussão na mídia. A partir daí, ampliou-se em larga escala o reconhecimento social do papel do Museu na preservação do patrimônio cultural da região, e ele se tornou um ponto de interesse da cidade.

Portanto, os capítulos que seguem apresentam uma análise teóricoempírica sobre como o turismo tem impactado a região, com a exploração de atrativos na perspectiva do mercado econômico, em que importantes referências do patrimônio cultural de Itá, como o Museu do Balseiro, dentre outros, têm sido ignoradas na dinâmica turística e cultural da cidade.

\section{As duas faces da cidade: a velha e a nova Itá}

O oeste do Estado de Santa Catarina foi povoado por diferentes grupos humanos e os efeitos dessas incursões geraram impactos ao meio ambiente. Antes do processo de colonização por migrantes descendentes de europeus, oriundos do Rio Grande do Sul, a região compunha-se por uma flora abundante, com 


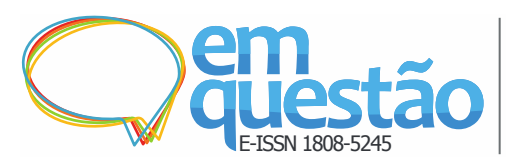

distintas espécies de árvores, tais como o cedro e o louro que viriam a ser, no início do século XX, um dos principais recursos econômicos explorados pela indústria madeireira. Dentre os primeiros grupos que usufruíram dos recursos das florestas, estão os indígenas caçadores-coletores, cuja presença na Mata Atlântica é datada, segundo evidências, em, no mínimo, onze mil anos. Embora seus modos de subsistência tenham transformado o território, a floresta se manteve em equilíbrio, diferentemente do que ocorre em relação ao grupo sucessor, no século XX, com a chegada de imigrantes vindos do Sul do país. (DEAN, 2004).

A presença indígena e cabocla na região, muito anterior à chegada dos colonos, se constituía de forma sustentável, quando os habitantes possuíam suas "terras de viver", onde construíam suas casas e cultivavam seus alimentos, “[...] como a farinha de beiju fabricada no monjolo ou a farinha de mandioca produzida na atafona." (RENK; SAVOLDI, 2008, p.3). Todavia, a paisagem e os seus modos de vida foram aos poucos sendo modificados pela ideologia de progresso e desenvolvimento de empresas colonizadoras que chegaram à região em 1919. Isso à semelhança do que ocorreu no Rio Grande do Sul, quando novos desbravadores desembarcam no oeste catarinense, no início da imigração europeia, e encontram um território impactado, com a presença de uma densa floresta, em convivência pacífica com populações indígenas e caboclas.

De modo idêntico ao que ocorreu no Sul do país, a instalação dos colonos na nova terra se constituiu num fator determinante do "[...] delineamento do mapa da devastação florestal do alto vale do rio Uruguai, no estado de Santa Catarina." (CABRAL; CESCO, 2008, p. 41). Em decorrência, o território protagonizado e constituído pelos primeiros habitantes sofre alterações, recebe novos valores e nele se formam novos caminhos e fronteiras (HOLANDA, 1957) instituídos com a chegada do colonizador. Daí decorre que, com o estabelecimento desse novo grupo de pessoas, o espaço é reconstituído por outros elementos culturais que se entremeiam no tecido social da vida cotidiana.

O início da década de 1920 se constitui num marco referencial da formação socioeconômica do oeste de Santa Catarina, com um exponencial 


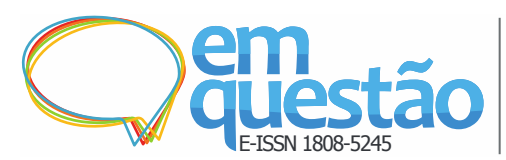

crescimento da região e a consequente instalação de núcleos urbanos, pela crescente presença de imigrantes. Tratava-se do início do ciclo da madeira, baseado no extrativismo vegetal, em especial da araucária, que se transformou em atividade econômica de destaque não só do oeste catarinense, mas do país. Esse período, sinônimo de apogeu econômico da região, foi, ao mesmo tempo, um doloroso momento de devastação das florestas e impacto no ambiente natural. A madeira, convertida no ouro da época, era extraída das matas e transportada em forma de balsas pelo rio Uruguai, com destino à Argentina e ao Uruguai, de onde eram exportadas para diferentes partes do mundo.

Sendo o único meio de transportar a madeira, o translado de balsas se transformou em ofício, surgindo daí os balseiros, homens de vida atribulada, que enfrentavam as cheias do rio, em condições insalubres, sobre balsas construídas de forma improvisada, produzidas da seguinte forma:

\begin{abstract}
As toras ou torradas, vocábulo empregado por muitos balseiros, eram colocadas uma ao lado da outra. As que possuíam o mesmo comprimento formavam o 'Pelotão'. Este era de 10 a 15 toras, amarradas a uma travessa de madeira de Lei forte, cuja espessura variava de 20 a $25 \mathrm{~cm}$ de diâmetro, chamadas pelos balseiros de 'lata'. A lata possibilitava a amarração e fixação da madeira. (BELLANI, 2006, p. 79).
\end{abstract}

Sem dispor de mapa, bússola ou qualquer outra ferramenta de navegação, o balseiro deveria conhecer o rio de cor e salteado, sobretudo os vinte e oito obstáculos presentes no trajeto. Apesar dos riscos e do longo tempo que ficavam distantes de seus lares, o trabalho oferecia boa remuneração. Desse modo, grande parte dos imigrantes se tornou balseiro, pela falta de outras opções de trabalho, ou por ter herdado a profissão.

Diante disso, empresas colonizadoras foram se instalando na região, em diferentes cidades do oeste, como na Vila de Itá, no vale do alto Rio Uruguai que, em decorrência da expansão agrícola, foi elevada à categoria de distrito, em 1924. Finalmente, emancipa-se de Concórdia na década de 1950, tornando-se município. Sua base econômica constituía-se na produção de uva, cachaça, açúcar, rapadura, marmelada, melado e bagaço de cana. 


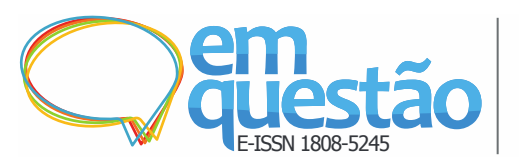

O Museu do Balseiro, criado pelo agricultor, turismólogo, filho, neto e bisneto de balseiro Nilo Brand, tem como objetivo recuperar os saberes e fazeres dos balseiros, numa casa cuja arquitetura faz referência aos primeiros migrantes alemães, como a de seu bisavô, um dos maiores exportadores de madeira da região. Assim, o culto ao passado, a possibilidade de aguçar as memórias daqueles que viveram na antiga cidade e vivenciaram outro tempo, em especial a figura dos balseiros e o ciclo da madeira, se transformaram em semióforos: "[...] objetos que não têm utilidade, no sentido que acaba de ser precisado, mas que representam o invisível e são dotados de um significado; não sendo manipulados, mas expostos ao olhar, não sofrem usura.” (POMIAN, 1984, p. $71)$.

Igualmente, as museália, objetos de museus, substituíram suas funções, características e usos originais, em dispositivos de interpretação cultural e de reconstrução de histórias e memórias. Desde então, o Museu do Balseiro exerce na nova Itá a importante função social de transmitir o ofício para as novas gerações, para que reflitam sobre o tempo presente, compreendam o passado e se apropriem da história e memória coletiva. A pequena propriedade da família Brand, denominada Recanto do Balseiro, tornou-se uma referência na região como um destino turístico e cultural. O recanto é um espaço híbrido em que a cultura, o lazer e a memória se imbricam e refletem os modos de ser de homens e mulheres do campo.

A nova Itá tem conquistado grande visibilidade turística. $\mathrm{O}$ investimento do setor na divulgação e criação de atividades para o lazer viabiliza a exploração local e o desenvolvimento econômico. No mesmo âmbito da Secretaria de Turismo está o setor cultural, compreendido como um potencial a ser explorado no município, desvinculado das políticas preservacionistas, ações de salvaguarda e sem a devida participação popular.

Desse modo, bens patrimoniais, saberes, fazeres, memórias e histórias de vida se encontram num fosso distante dos focos de interesses do poder público, como veremos no capítulo seguinte, resultando em práticas segregadoras e conflituosas. 


\section{Turismo e patrimônio cultural: sedução e armadilhas}

Na década de 1970, Itá depara com o seu maior dilema, quando a cidade foi inundada para a construção de uma hidrelétrica que represou a água do rio Uruguai, cobrindo todo o seu território. Isso exigiu que as famílias fossem indenizadas, e a cidade reconstruída numa região mais alta. Da cidade velha, inundada pelas águas, restaram visíveis apenas as torres da antiga igreja, que se constituem em ponto turístico e patrimônio cultural, uma vez que elas exercem uma função social e simbólica para o grupo que vivenciou a transição e transformação do lugar.

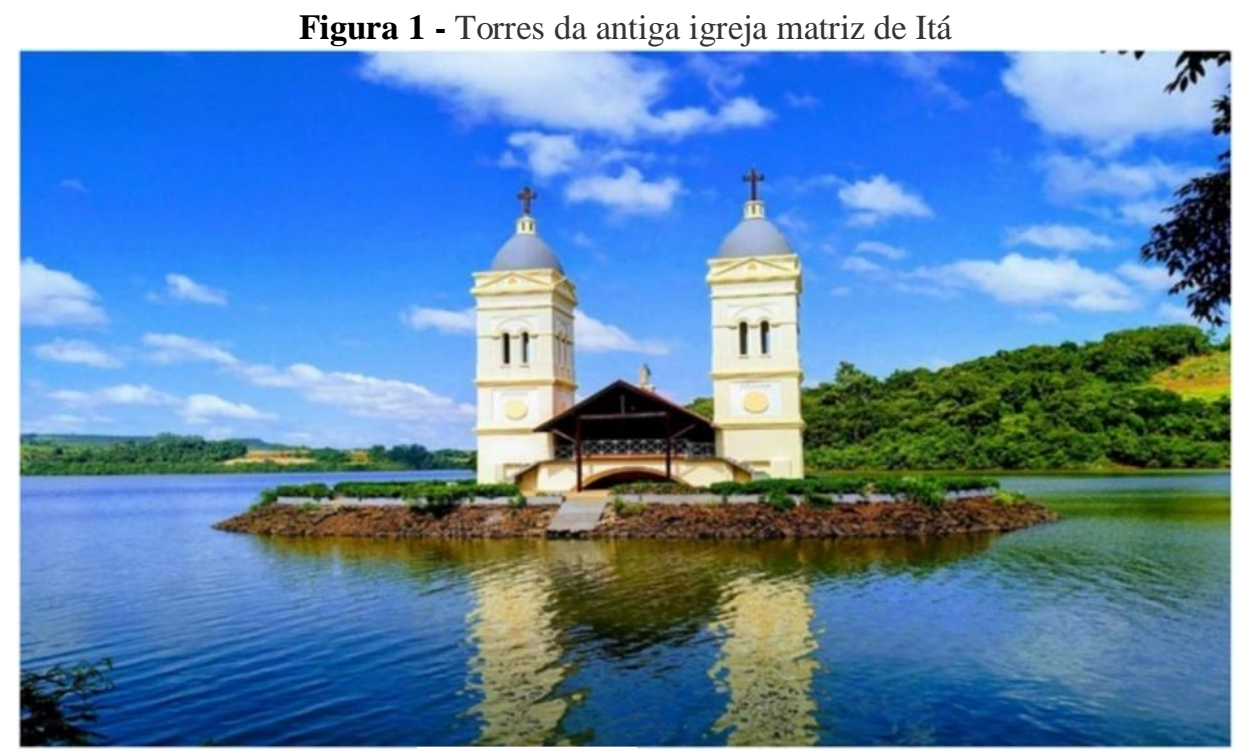

Fonte: Governo de Itá (2018).

As torres da igreja exercem um papel de mediação fundamental para a compreensão das mudanças e transformações do local, como uma passagem entre "[...] o passado, o presente e o futuro dos grupos assegurando a sua continuidade no tempo e sua integridade no espaço." (GONÇALVES, 2007, p. 28). Eleitas como uma das marcas da identidade local, a preservação das torres pode ser percebida como uma forma de anestesiar os conflitos com a comunidade e os problemas socioambientais causados pela instalação da usina. Promovidas por belas imagens e um intensivo trabalho midiático, as torres são um dos principais chamarizes do turismo itaense. 


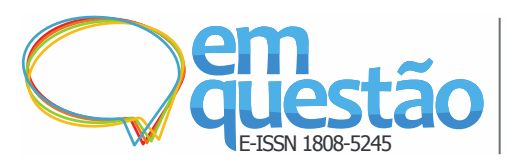

Para promover o desenvolvimento da nova cidade, a Prefeitura Municipal elegeu o turismo como o seu elemento mais importante na economia da região. Todavia, para a sua implementação, não houve qualquer consulta à comunidade, que, desse modo, não conseguiu ser ouvida sobre o que constitui o seu patrimônio cultural. No site da Secretaria de Turismo, são apresentadas diferentes alternativas para os turistas (GOVERNO DE ITÁ, 2019a), como roteiros aquáticos, de aventura, de arvorismo, ecoparques, rural e, no campo do que interessa a este trabalho, um roteiro cultural. Trata-se de um modelo que inclui atividades comuns a diversos outros programas de turismo dispersos pelo planeta, e que poderiam fazer parte de ofertas de outras centenas de cidades. Em que pese que o roteiro destaque e valorize o ambiente natural, evidencia-se que ele praticamente não valoriza o patrimônio cultural da região. Isso permite que se afirme que ele apresenta certa distância de um plano que possa ser considerado como original, próprio, particular e genuíno da cidade de Itá.

Especificamente no roteiro cultural, cujo slogan é Para reviver o passado, foram omitidos diversos pontos de interesse cultural do município, caso do Museu do Balseiro, localizado no Recanto do Balseiro, marco histórico por ter sido um dos principais acessos ao Rio Uruguai, utilizado para o transporte das toras de madeira. Desse modo, percebe-se que a Secretaria de Turismo ignora a instituição, como referência do patrimônio cultural do Município, entretanto, supervaloriza os demais museus situados no centro da cidade. A administração atual não se preocupou, até agora, em ouvir a direção do museu nem outras pessoas representativas da comunidade para a construção da memória do lugar. As torres e os demais pontos de interesse elencados pela secretaria são escolhidos na perspectiva de um tipo de turismo que considera apenas as necessidades do mercado, visando ao lucro e ao fortalecimento da economia local, deixando de lado o patrimônio cultural constituído pelas pessoas, suas histórias e memórias.

O turismo, por si só, é uma atividade que exige cuidado, por se voltar ao lucro, apesar de o discurso da sustentabilidade ser fundamental para a construção de sua base. Embora o turismo possa se constituir numa atividade voltada à promoção do desenvolvimento local, Varine (2012) ressalta que “[...] 


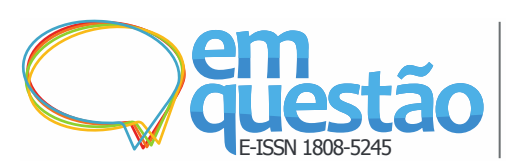

todo território determinado sem o respeito por seus componentes patrimoniais não poderá servir de base para um desenvolvimento local equilibrado e sustentável " (VARINE, 2012, p. 19). Ou seja, no caso de Itá, ainda que o turismo tenha se transformado na atividade econômica local mais importante, seus habitantes, entendidos pelo autor como seus componentes patrimoniais, não foram ouvidos, nem incluídos.

Ao analisar a relação entre patrimônio cultural e turismo, Benhamou (2016) alerta que, ao invés de multiplicador, o turismo pode ser tão só uma armadilha, já que seus efeitos sobre a economia são ambivalentes, ao provocar “[...] uma atração por atividades eventualmente menos produtivas e socialmente menos úteis do que outras" (BENHAMOU, 2016, p.85). Portanto, o seu impacto econômico por meio do turismo cultural deve ser repensado. Trata-se, pois, segundo a autora, de um discurso sedutor, que pode se constituir num artifício.

Como atrativos turísticos, o roteiro dá ênfase especial ao turismo aquático, a partir dos empreendimentos Itá Thermas Resort e Itá Parque Hotel ${ }^{1}$, extremamente valorizados e com custos bem elevados, que disponibilizam um acesso exclusivo ao Rio Uruguai. Para o atual secretário de Turismo do município, Altir Goedert:

O lago é nosso principal atrativo, temos também o Parque Thermal que tem características próprias, as Torres da Igreja que são um cartão postal e vamos trabalhar com a questão histórica, ou seja, temos vários pontos para explorar e atrair mais turistas. E não podemos esquecer da nossa população, que também é um diferencial positivo. (GOVERNO DE ITÁ, 2017, doc. não paginado).

O plano de desenvolvimento econômico por meio do turismo foi consolidado numa parceria entre a Secretaria de Turismo, juntamente às empresas turísticas Itá Eco e Eco\&Eco, cuja meta é transformar a região no maior polo turístico do Estado de Santa Catarina até 2025:

O município de Itá vem semeando para colher em breve grandes oportunidades. Assim, podemos descrever o amplo trabalho que vem sendo realizado pelo GETTUR - Grupo de Estudos e Trabalhos Turísticos de Itá. O Itá Eco Turismo é um dos grandes parceiros do GETTUR na busca de um objetivo macro, transformar a cidade de 
Itá como destino preferido do interior de Santa Catarina até 2025. (ITÁ ECO TURISMO, 2017, doc. não paginado).

Para alcançá-la, novos equipamentos têm sido criados, como tirolesas, um bonde funicular, que liga a parte central da cidade às principais rotas turísticas no entorno do lago formado pela construção da usina. O contato excessivo com a natureza requer atenção redobrada, isto é, a implantação de ações e políticas voltadas à preservação do meio ambiente e da privacidade dos moradores locais. Todavia, é necessário frisar que nem todos aqueles que se dedicam ao setor turístico estão preocupados com o desenvolvimento local, em sintonia com os princípios ambientais, ou interessados em preservar seu patrimônio cultural.

A Usina Hidrelétrica de Itá, por exigência legal, criou o Centro de Desenvolvimento Ambiental (CDA), como medida de compensação pelos impactos ambientais, sociais e econômicos que a empresa causou na região. $\mathrm{O}$ centro, desde então, desenvolve programas e projetos de educação ambiental, destinados à integração dos moradores que se concentram no entorno do reservatório, que, de um momento para outro, foram afastados de seu lugar de origem. Ou seja, transformaram-se em vítimas de um processo de profunda desterritorialização.

Esse fenômeno se constitui pela transição de um lugar, com o deslocamento do local de origem de uma comunidade (DELEUZE; GUATTARRI, 1997). Trata-se do processo de mudança do território, uma realocação espacial de um grupo para uma nova morada, o que implica num procedimento de reorganização social, composto em novos valores, práticas e saberes. A desterritorialização da antiga Itá provocou um novo movimento, o de reterritorialização, isto é, de nova configuração do espaço urbano e das relações de sociabilidade:

Diante da massa de despossuídos do planeta, em índices de desigualdade social e de exclusão cada vez mais violentos, o 'apegar-se à terra', a reterritorialização é um processo que vem ganhando força. Ele se torna imprescindível não somente como fonte de recursos para a sobrevivência física cotidiana, mas também para a recriação de seus mitos, de suas divindades ou mesmo para manter viva a memória de seus mortos. (HAESBAERT, 1999, p. 185). 


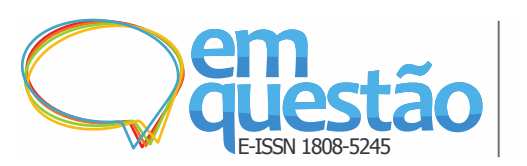

Em consequência, a reterritorialização de Itá fez emergirem novas identidades, bem como a afirmação de memórias daqueles que vivenciaram a transição espacial do antigo para o novo lugar. Trata-se do que Hobsbawm (1987) define como tradição inventada, em que movimentos, instituições políticas ou grupos, na tentativa de valorizar uma realidade atual problemática, “[...] criam um passado antigo que extrapole a continuidade histórica real seja pela lenda [...], ou pela invenção [...]" (HOBSBAWM, 1987, p. 15). No caso de Itá, a invenção de uma tradição pode ser identificada na ênfase dada à recuperação das memórias dos balseiros, considerados como vilões pela História oficial do país, por sua vinculação à ação dos madeireiros, que, ao invés dos primeiros, enriqueceram a exploração da Mata Atlântica e do quase desaparecimento das araucárias.

A invenção de uma continuidade histórica em Itá é percebida na preservação das torres submersas, na Pedra Fundamental, símbolo da origem e desenvolvimento da nova cidade (Figura 2), bem como na realocação das casas dos primeiros colonizadores que foram transformadas em museus. Disso resulta numa história local, e suportes da memória coletiva construídos no novo território, artificiais. Segundo o historiador, toda tradição inventada "[...] utiliza a história como legitimadora das ações e como cimento da coesão grupal.” (HOBSBAWM, 1987, p. 22). Portanto, são símbolos de uma identidade criada para representar a nova história itaense e servir como base aos discursos políticos de ordem nacionalista.

Símbolo de uma nova trajetória para Itá e do seu desenvolvimento econômico, a Pedra Fundamental, constante na Figura 2, representa a construção da nova cidade (GOVERNO DE ITÁ, 2019b). A sua base de sustentação é feita em sassafrás, madeira que representa o ciclo dos balseiros, decorada com as cores da bandeira de Santa Catarina. 

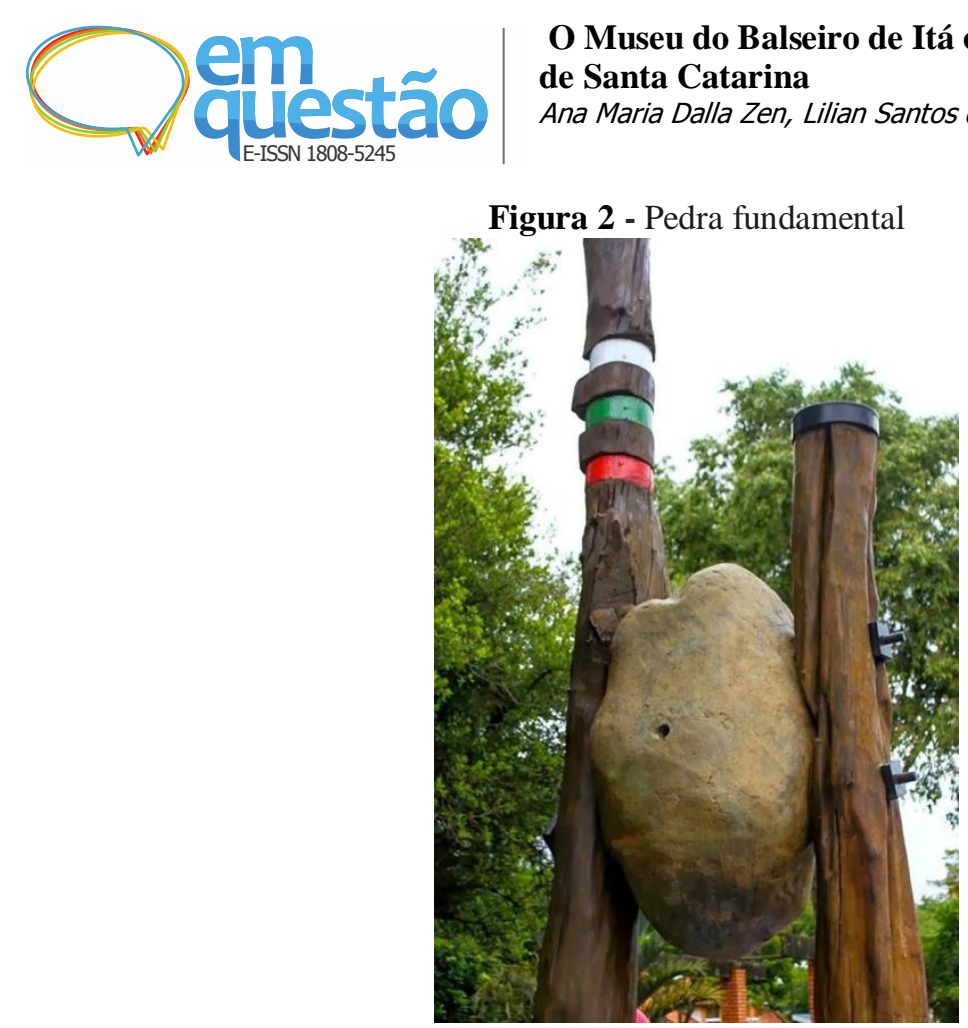

Fonte: Silveira (2014).

Muito além da destruição de casas e demais espaços de vivências, as águas levaram o sentimento de pertença da população. Todavia, o culto da memória permaneceu vivo, a ponto de, na cidade nova tenham sido criados cinco museu, a saber: Alberton, Camarolli, Museu do Rádio, Museu do Centro de Divulgação Ambiental e Museu da Garrafa, numa cidade de dois mil habitantes.

Os museus-casas Alberton e Camarolli, transferidos para o novo território, são identificados pela prefeitura como as principais instituições da cidade, por fazerem referência à memória das famílias colonizadoras reconhecidas pela história oficial local. Para celebrar a memória dos empregados, ou seja, dos peões dos madeireiros, o Museu do Balseiro foi criado para ser um espaço de representação e afirmação da identidade balseira. Homens que desbravaram o sertão do oeste catarinense atuando numa atividade rude e difícil, não por opção, mas por ter sido praticamente essa a única forma que dispunham para manterem suas famílias com alguma dignidade.

O Recanto do Balseiro é um empreendimento de turismo rural que tem contribuído para recriar identidades familiares e comunitárias. De acordo com Pereiro Pérez (2009): “[...] o turismo adotou e adota as formas sociais de cada época e sociedade. Também é certo que o turismo rural tem sido produtor e não 


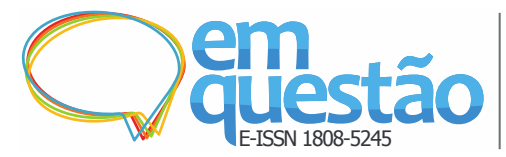

O Museu do Balseiro de Itá como patrimônio cultural de Santa Catarina

Ana Maria Dalla Zen, Lilian Santos da Silva Fontanari

só produto, tendo um papel importante no desenvolvimento local." (PEREIRO PÉREZ, 2009, p. 257). Nesse sentido, trata-se de uma estratégia para o desenvolvimento econômico. Todavia, sem que haja o devido planejamento, qualquer ação corre o risco de se converter em ameaça ao meio ambiente e patrimônio.

No mesmo local de onde partiam as balsas pelo Rio Uruguai, foi criado o Museu do Balseiro. Composto por um acervo que reúne mais de quinhentas peças do cotidiano e do ofício de balseiro, entre as quais ferramentas, utensílios e móveis da época, o local vem transformando-se em local de memória e de preservação do patrimônio cultural, de grande significado para os moradores da região. Na Figura 3, percebe-se que, logo na entrada do museu, foram expostas dezenas de fotografias dos balseiros e de suas viagens.

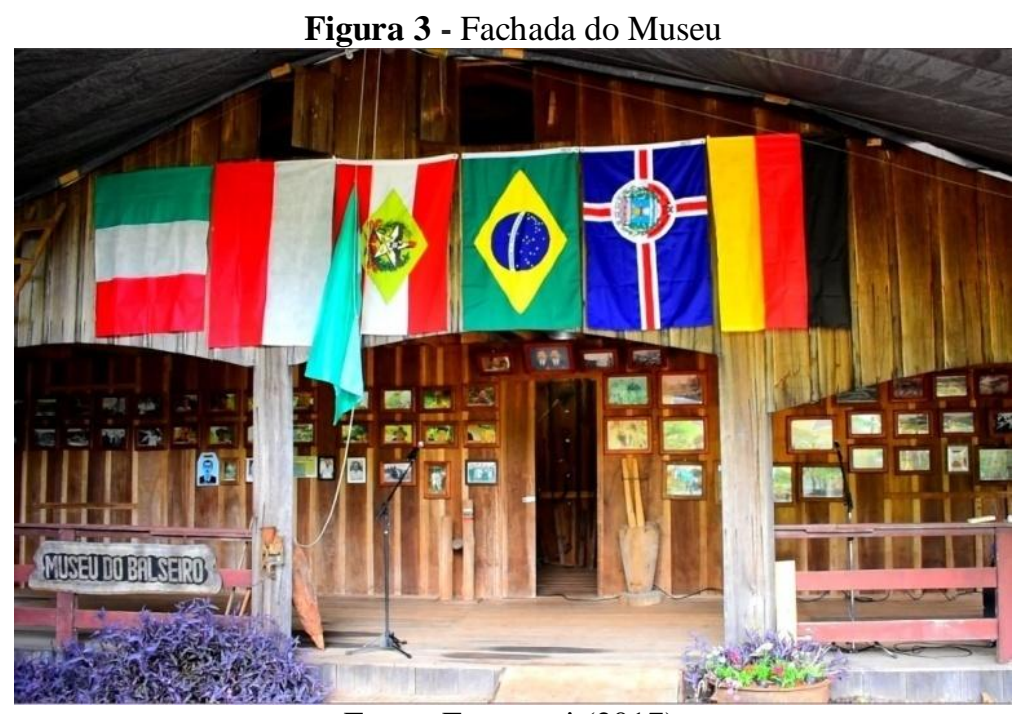

Fonte: Fontanari (2017).

Desde a sua abertura, o museu realiza encontros anuais intitulados Desbravadores do Rio Uruguai, que reúnem os balseiros e suas famílias para reativar o passado, renovar os laços de pertença e compartilhar sonhos. Nessa data, uma festa marca o dia, com cultos religiosos, comidas típicas, acompanhados por danças e a execução do Hino dos Balseiros, composto pela música do cantor Cenair Maicá (Balseiros do Rio Uruguai) ${ }^{2}$, interpretado por crianças da rede municipal de ensino. Muito além de um simples dia de lazer, o 


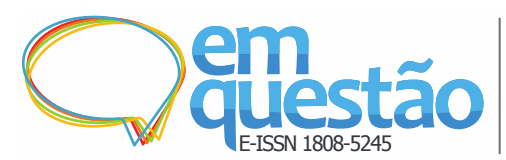

encontro permite que o grupo reafirme a sua identidade, vindique o seu reconhecimento e a sua inserção na história oficial da cidade.

\section{0 projeto Itá, ontem hoje e amanhã}

A possibilidade de patrimonialização do cotidiano dos balseiros é resultado da profunda mudança de paradigma ocorrido no campo dos museus na década de 1970, quando é reconhecido o seu papel sociocultural, com a ideia de museu integral, em cujos “[...] alicerces encontrava-se o princípio da democracia participativa, que começava a ver a luz, mas também o reconhecimento do capital social como eixo de coesão e desenvolvimento." (QUEROL; SANCHO, 2014, p. 3).

Embora a Organização das Nações Unidas para a Educação, a Ciência e a Cultura (UNESCO) já houvesse discutido o tema em 1958, durante o Seminário Regional sobre o Papel Pedagógico dos Museus (RIVIERE, 1958), foi somente em 1972, com a Declaração de Santiago (ICOM, 1972), que reconheceu a função social dos museus, com base no conceito de museu integral. Todavia, foi na década de 1980 que o movimento da Nova Museologia, liderado por George-Henri Rivière e Hugues de Varine-Bohan, se solidificou, reivindicando a constituição de novas experiências e formas de comunicação entre os museus e a sociedade. Tratava-se da uma inovadora forma de museu, na qual “[...] não há um edifício, mas um território-museu, e que não centra sua atenção nas coleções, mas em todo o ecossistema humano, o que inclui elementos da cultura material e também imaterial " (LORENTE, 2012, p. 67), que se concretizava através da criação de ecomuseus e museus comunitários.

Segundo Soares e Scheiner, (2009, p.1), com os ecomuseus e os museus comunitários, a Museologia ampliou seus horizontes e "[...] nos leva a pensar o museu como um espaço do habitar." (SOARES; SCHEINER, 2009, p. 1). Esse habitar significa espaço de vivência, de relações sociais, laços, interações, regras, acontecimentos, enfim, o nosso núcleo familiar; local em que se estabelece, também, o patrimônio cultural. Desse modo, com a Nova 


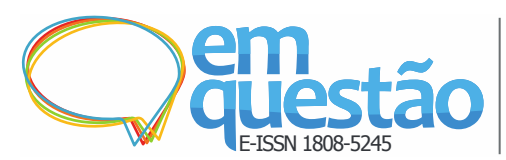

Museologia, permitem-se "[...] inusitadas formas de criação usadas pelas sociedades para gestar e processar um museu que se incorpora à vida, que integra suas ações cotidianas." (VARINE; PRIOSTI, 2007, p. 59). Nesse sentido, é fundamental que ele seja compreendido por meio de seu percurso temporal, uma vez que:

[...] envolve tanto o papel da memória e da tradição na construção de identidades coletivas, quanto os recursos a que têm recorrido os Estados modernos na objetivação e legitimação da ideia de nação. Permeando essas dimensões, está a consideração do uso simbólico que diferentes grupos sociais fazem de seus bens - e aqui me refiro tanto à produção quanto à conservação ou destruição - na elaboração das categorias de espaço e tempo. Ou seja, o valor que atribuem a esses bens enquanto meios para referir o passado, proporcionar prazer aos sentidos, produzir e veicular conhecimento. (FONSECA, 2009, p. 51).

A sua apropriação é necessária para que o grupo social valorize e preserve suas memórias e sua herança cultural, o que se torna possível por meio de ações de Educação para o Patrimônio (EP), que, segundo Grinspum (2000, p. 30) se constitui numa possibilidade de

[...] interpretar objetos de coleções dos museus, do ambiente natural ou edificado, atribuindo-lhes os mais diversos sentidos, estimulando-os a exercer a cidadania e a responsabilidade social de compartilhar, preservar e valorizar patrimônios com excelência e igualdade (GRINSPUM, 2000, p. 30).

Nesse sentido, educar para e com o patrimônio permite ao indivíduo refletir sobre a sua inserção no tempo-espaço e potencializar os seus laços de pertencimento.

Para Le Goff (2010), “[...] a memória, na qual cresce a história, que por sua vez a alimenta, procura salvar o passado para servir ao presente e ao futuro " (LE GOFF, 2010, p. 471). De acordo com Le Goff (2010), é importante que se trabalhe de forma que a memória coletiva sirva para a libertação e não para a servidão dos homens. Libertação seria a palavra chave para o processo de desenvolvimento e de transformação dos lugares. A memória pode ser o meio para essa libertação, para recompor particularidades do passado, fortalecer 


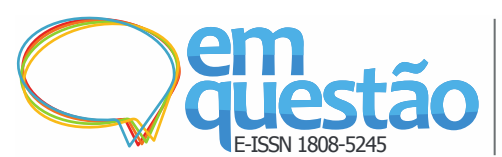

vínculos e construir e reforçar identidades. No entanto, fazer da memória, do passado, local de abrigo, de refúgio, é se fechar para o novo, para possíveis soluções de problemas na estrutura das sociedades.

Assim como a memória, o patrimônio cultural desempenha um papel fundamental na reconstrução das identidades, da história oficial e dos sujeitos comuns. Desde 2013, é realizado, sempre no último sábado de setembro, o Encontro dos Balseiros, evento para relembrar as histórias e reativar a memória do grupo. Os antigos balseiros e suas famílias participam da construção da festa que, desde os primeiros preparativos se flagram submersos em sentimentos de nostalgia. A festa exerce um papel decisivo na continuidade e reconstrução do grupo, bem como na transmissão do ofício do balseiro às novas gerações. Foi por meio desses encontros que o museu estabeleceu parceria com a escola local, na expectativa de inserir a história do balseiro e do período da atividade extrativista no currículo escolar. Da relação entre museu e escola surgiu um projeto, em 2016, que vem sendo realizado e aprimorado até o momento presente, permitindo aos mais jovens, com ou sem parentesco com os balseiros, a apropriação da identidade do grupo, por uma história não contada nos livros escolares, numa espécie de história não oficial.

O papel educativo do museu pode ser expresso de diversas formas, seja por meio de uma exposição, de uma oficina ou conversa. No entanto, não é apenas na redoma museal que o papel educativo e social pode ser desenvolvido, explorado, alcançado. Desde o Seminário Regional da UNESCO, em 1958, a comunidade museológica tem reafirmado que os museus são espaços educativos por excelência. Sendo o público escolar o seu maior adepto, o museu tem a incumbência de criar ações e interrelações que reforcem a laços dessa união.

O Projeto Itá, ontem, hoje e amanhã, concebido pela educadora Mara Suhre $^{3}$ e realizado com os alunos do quarto ano da Escola Municipal Valentin Bernardi, inaugurou a parceria entre as ações educativas e culturais do Museu do Balseiro com as iniciativas do sistema escolar. Executado no ano de 2017, o projeto tinha como objetivo (re)conhecer e recuperar a história da região, dos balseiros e suas práticas, que incluem a produção de artefatos, meios de transporte e ferramentas de trabalho, produzidos a partir do conhecimento oral, 


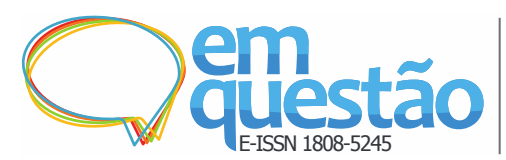

como forma de aproximar as crianças de suas próprias histórias, uma vez que muitas delas se originam de famílias de balseiros. Desse modo, a escola e o museu iniciaram uma ação conjunta para valorizar as memórias que constituem a herança cultural do município e incentivar o seu reconhecimento pelas novas gerações, que assim é descrito por sua idealizadora:

O projeto que está se desenvolvendo dentro do Turismo e Sustentabilidade foca muito na história do nosso município de Itá, a importância das crianças conhecerem a sua história, conhecerem a história do município. A gente faz um resgate da história dos primeiros colonizadores, e o foco muito grande dentro da história da colonização é a história dos balseiros.

A gente vem até aqui (Museu do Balseiro), participa, traz as crianças para conhecer a história dos balseiros. O Seu Nilo foi até a nossa escola, nos contou sobre os balseiros, então eles (as crianças) têm que se aprofundar, por quê? Por que uma pessoa sem história é uma pessoa sem identidade, então faz parte da história da família deles, faz parte da história deles. Muitos deles têm avós, bisavós que foram balseiros.

Por isso a gente vê a importância de essas crianças, hoje com nove, dez anos, conhecer a história dos antepassados deles. E os balseiros geraram toda uma economia de uma época, então nós, com a escola desenvolvemos um projeto pra falar exatamente sobre isso dentro do Projeto Turismo e Sustentabilidade (ENCONTRO NACIONAL E REGIONAL DOS BALSEIROS DO RIO URUGUAI, 2017, doc. não paginado).

A instituição escolar é um espaço permanente e contínuo de negociação, em que as diversidades culturais, étnicas e sociais transformam-se em estratégia para o fortalecimento de pertença, respeito à diferença e reforço da identidade. As crianças dessa escola estão preparadas para responder a perguntas sobre a era madeireira e a sua economia, o ofício de balseiros, os impactos gerados à região e a relação desse movimento e pessoas com a suas histórias de vida, uma vez que a nova geração descende de homens e mulheres que protagonizaram e vivenciaram o cenário do extrativismo vegetal.

Ao inserir a problemática do patrimônio cultural na escola, é possível realizar a incursão de novas formas de ação educativa úteis, para subsidiar as atuais circunstâncias do mundo contemporâneo. Por meio de uma ação comunitária, nove disciplinas foram envolvidas no referido projeto: Português, Matemática, História, Ciências, Geografia, Informática, Música, Turismo e 


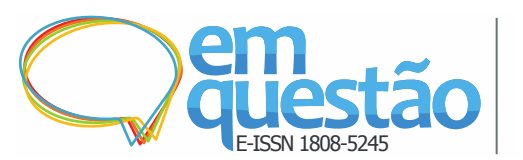

Inglês, cujos conteúdos específicos de cada área foram sendo relacionados com os diferentes aspectos da colonização na região, da atividade extrativista e suas histórias de vida, resultando, desse modo, na construção da memória social e coletiva. A iniciativa se constituiu numa forma eficiente para observar como o ser humano vai modificando o lugar onde vive, adaptando conforme suas necessidades e identificando as transformações que ocorreram no município com o passar do tempo. A metodologia incluiu a realização de duas rodas de memórias com balseiros, que explicaram todo o processo, acompanhadas da análise documental de fotografias e documentos, bem como da produção de cartazes que focalizaram as modificações sofridas pelo ambiente a partir da extração da madeira.

Nos encontros, eram discutidos os motivos da escolha do tipo de madeira, quais eram as técnicas de corte, quais os passos para a construção e o manejo da balsa. Qual era a madeira utilizada? Como o cipó era amarrado? O que acontecia a partir da derrubada das árvores? Quais ferramentas eram utilizadas? E hoje, seria possível uma balsa descer o Rio Uruguai? Como era a região antes e depois da derrubada das árvores? Hoje, ainda seria possível construir uma balsa com essas árvores? Por quê? Qual é o impacto ambiental provocado pela ação dos balseiros? Essas perguntas permitiram uma aproximação entre as três gerações, ou seja, a dos balseiros, a dos professores e a dos alunos, numa ação educativa de valorização e reconhecimento daquela atividade e de uma contextualização mais humana e solidária desta, considerada tradicionalmente apenas por seu lado predatório e impactante. Finalmente, sob a orientação de quatro balseiros, na Figura 4 observa-se os alunos iniciando a construção da maquete de balsa: 


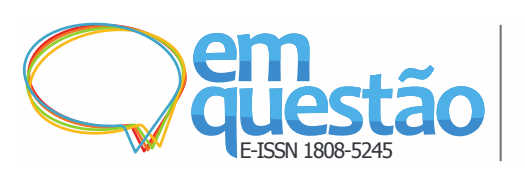

Figura 4 - Confecção de balsa com os alunos da Escola Valentin Bernardi

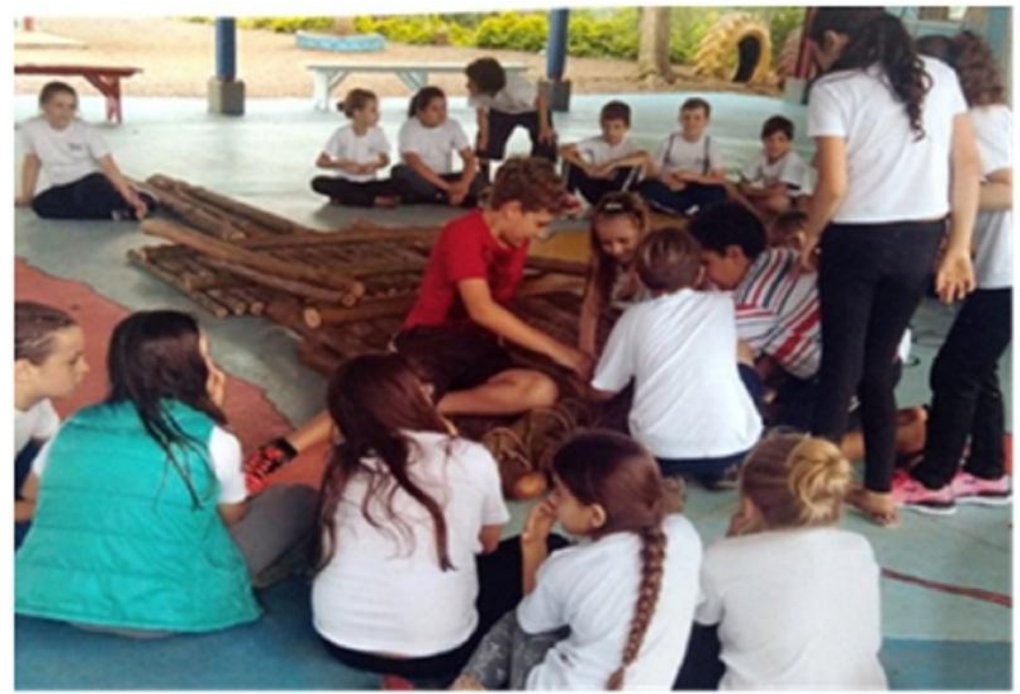

Fonte: Suhre (2016).

Embora o trabalho realizado pela educadora não tenha se baseado no conceito de Educação para o Patrimônio, é possível identificar alguns pontos de convergência com esse conceito. O primeiro passo é a contextualização do aluno em relação ao tempo e ao espaço. De que lugar e contexto histórico estão falando? Em sequência, é feita a apresentação de um elemento do patrimônio local que represente uma memória coletiva, como, por exemplo, o ofício dos balseiros e a preservação das torres da igreja. Essas questões podem nortear a construção de conhecimento acerca do processo histórico de um bem patrimonial que é coletivo, plural. Em se tratando de território, a Educação para o Patrimônio tem potencial de levantar discussões sobre pertencimento, identidade e apropriação do espaço, relacionando, nesse sentido, as ações cotidianas, os sentidos e usos do lugar em que se processa e se constrói a vida.

Desconsiderado pelo poder público local, o Museu do Balseiro é uma das poucas instituições que desenvolvem atividades integradas à comunidade escolar itaense. A realidade dos museus públicos e privados de Itá se assemelha em um ponto: nenhum dispõe de profissional qualificado para o exercício de gestão das instituições. Mesmo com dificuldades financeiras, falta de uma equipe técnica, o Museu do Balseiro demonstra que é possível realizar um trabalho em conjunto com a população, que atende e inclui as demandas do local. Portanto, ao realizar o trabalho de preservação e transmissão da história e 


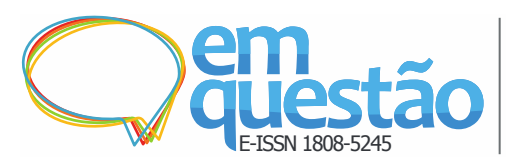

do ofício do balseiro, em conjunto com a comunidade, oportunizando aos sujeitos o papel de protagonista, o museu colabora na construção do conhecimento e do sentimento de pertença tão importantes para a recuperação das identidades e para o conhecimento crítico.

\section{Considerações finais}

Este trabalho buscou analisar e compreender o modo como o Turismo tem sido trabalhado no campo do patrimônio cultural, e de que forma um projeto escolar concebido na perspectiva do Turismo e da Sustentabilidade, com ações que se caracterizam em Educação para o Patrimônio, tem sido negociado e associado à história local. A pesquisa revelou que, apesar dos impactos da ação madeireira no meio ambiente, o ofício se constitui em patrimônio cultural da região, reconhecido pela comunidade. O projeto Itá: ontem, hoje e amanhã, aproximou diferentes gerações e permitiu a reconstrução de memórias e a afirmação da identidade itaense.

A análise dos roteiros turísticos e culturais oferecidos pela Secretaria de Turismo exigiu que se refletisse sobre como o turismo tem impactado o setor de cultura, com a exploração dos bens culturais na perspectiva do mercado econômico. Mas, ainda mais problemático, mostrou como o Museu do Balseiro, bem como os demais elementos que constituem o patrimônio cultural de Itá, têm sido pouco, ou praticamente nada, inseridos na dinâmica turística e cultural da cidade.

Ao longo do texto, o Museu do Balseiro foi referido como um lugar de produção e transmissão de cultura, conhecimento e de construção da identidade do grupo que faz referência. A integração entre o museu e a escola tem permitido que os alunos reflitam sobre o impacto e a degradação ambiental causada pelas madeireiras, bem como sobre os motivos que levaram os balseiros a optarem por esse ofício. Nem vilões, nem heróis, os balseiros são pessoas que lutaram por suas vidas, famílias e utopias, dentro das condições que lhes eram 


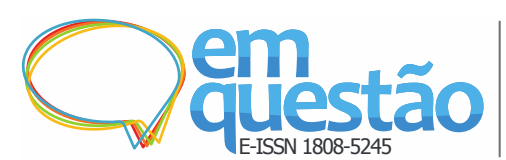

possíveis. Apenas agentes históricos, num ambiente inóspito, difícil, cujos saberes e fazeres tornaram-se patrimônio local.

Como vimos, a nova sede de Itá exigiu que novos símbolos fossem criados para representar a sua identidade. As torres da antiga igreja e a Pedra Fundamental marcam esse movimento de tradição inventada, como forma de estabelecer a coesão, a união dos grupos. São esses símbolos e espaços, os cartões de visita da cidade, que vem sendo explorados pelo turismo, assim como os museus mantidos pela prefeitura.

Sabe-se que os lugares, os museus e as práticas sociais não estão isentos de interesses e manifestações de poder político e econômico. E, mesmo que as ações turísticas sejam realizadas numa perspectiva do desenvolvimento sustentável, precisam ser negociadas, reduzir conflitos e evitar decisões impostas de cima para baixo. Numa realidade em que não há abertura para a população participar do processo de definição do turismo que quer, a atividade se manterá tão só e exclusivamente na dimensão do lucro para poucos, como vem ocorrendo em diferentes lugares do planeta. Sem incluir os diversos componentes humanos, históricos e culturais que identificam o patrimônio local, certamente, o resultado será de uma tragédia anunciada para o patrimônio e para a diversidade cultural do território. Desse modo, se a região já sofreu com a extração da madeira na década de 1920, um turismo que se diz sustentável apenas no discurso pode ocasionar um novo desastre ambiental na cidade, em pleno século XXI.

As experiências museais e o desejo pela memória entre os moradores de Itá estão em sintonia com os fundamentos da Nova Museologia, de valorização do ser humano, de suas histórias de vida e de seu território, que, devidamente sincronizados com a ação escolar, tornam-se estratégias importantes para uma educação humanizadora. A tríade Museu, Museologia e Patrimônio, se construída por meio da transversalidade entre cultura, história e memória, indica um rumo humanista e inclusivo para a educação das novas gerações.

A aproximação entre patrimônio e educação permite ampliar o campo de atuação tanto do museu quanto da escola. A inclusão de questões ligadas ao 


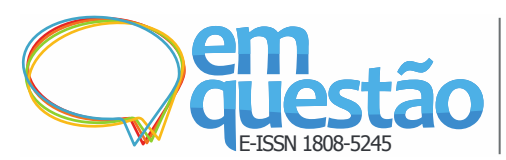

cotidiano dos alunos incentiva entre eles a apropriação, o pertencimento e a preservação do patrimônio cultural. A experiência de construção da balsa, por sua vez, se constituiu numa atividade de ação educativa, útil como estratégia de recuperação de memórias e de educação para o patrimônio, pelo reconhecimento, sob um novo olhar, dos elementos da cultura dos balseiros.

\section{Financiamento}

Trabalho realizado com apoio financeiro da Coordenação de Aperfeiçoamento de Pessoal de Nível Superior (CAPES) por meio da concessão de bolsa de mestrado.

\section{Referências}

BELLANI, Eli Maria. Balsas e balseiros no Rio Uruguai (1930-1950).

Cadernos do CEOM, Chapecó, v. 19, n. 23. p. 73-97, 2006.

BENHAMOU, Françoise. Economia do patrimônio cultural. São Paulo: SESC, 2016.

CABRAL, Diogo de Carvalho; CESCO, Susana. Notas para uma história da exploração madeireira na Mata Atlântica do sul-sudeste. Ambiente e Sociedade, Campinas, v. 11, n. 1, p. 33-48, 2008,

DEAN, Warren. A ferro e fogo: a história e a devastação da Mata Atlântica brasileira. São Paulo: Companhia das Letras, 2004.

DELEUZE, Gilles.; GUATTARI, Félix. Mil platôs: capitalismo e esquizofrenia. São Paulo: Editora 34, 1997. v. 5.

ENCONTRO NACIONAL E REGIONAL DOS BALSEIROS DO RIO URUGUAI [Documentário]. Produção de Lilian Fontanari et. al. Imagens: Gerliani Mendes. Montagem: Kevin Nicolai. Itá, Santa Catarina, 2017. 1 vídeo (28:43). Disponível em: https://mega.nz/\#!i2BzGY5B!Pt4Ml-Ei-mWqmp8yot2SY3OdCnnzJ1TAeOaZ7D5SqM Acesso em ago de 2018.

FONSECA, Maria Célia Londres. O patrimônio em processo. Rio de Janeiro: UFRJ, 2009.

FONTANARI, Lilian. A entrada do Museu. Plano Museológico do Museu do Balseiro, 2017. No Prelo. 
GONÇALVES, José Reginaldo Santos. Antropologia dos objetos: coleções, museus e patrimônios. Rio de Janeiro: IPHAN, 2007.

GOVERNO DE ITÁ. Notícias/Administração: Altir Goedert assume Secretaria de Turismo. Itá: Município de Itá, 2017.

GOVERNO DE ITÁ. Notícias/Obras: Prefeitura conclui restauração das Torres da Igreja submersa. Itá: Município de Itá, 2018.

GOVERNO DE ITÁ. Município de Itá. Mapa turístico. Itá: Município de Itá, 2019a.

GOVERNO DE ITÁ. Município de Itá. Praça Central. Itá: Município de Itá, 2019b.

GRINSPUM, Denise. Educação para o patrimônio: Museu de arte e escola responsabilidade compartilhada na formação de públicos. 2000. Tese (Doutorado em Linguagem e Educação) - Faculdade de Educação, Universidade de São Paulo, São Paulo, 2000.

HAESBAERT, Rogério. Identidades territoriais. In: ROSENDAHL, Z.;

CORREAA, R. L. (org.). Manifestações da cultura no espaço. Rio de Janeiro: EdUERJ, 1999. p. 169-190.

HOBSBAWM, Eric. Introdução: a invenção das tradições. In: HOBSBAWM, E.; RANGER, T. (org.). A invenção das tradições. Rio de Janeiro: Paz e Terra, 1987. p. 9-23.

HOLANDA, Sérgio Buarque de. Caminhos e fronteiras. São Paulo: Companhia das Letras, 1957.

ITÁ ECO TURISMO. Itá Eco integra GETTUR para alavancar turismo em Itá. Itá: Ideia Good, 28 nov. 2016.

LE GOFF, Jaques. História e memória. Campinas: Unicamp, 2010.

LORENTE, Jesús Pedro. Manual de historia de la Museologia. Gijón: TREA, 2012. (Manuais de Museística, Patrimonio y Turismo Cultural, 9).

MAICÁ, Cenair. Balseiros do Rio Uruguai. In: Álbum: Rio De Minha Infância [1978].

PEREIRO PÉREZ, Xerardo. Turismo Cultural: uma visão antropológica. El Sauzal: Asociación Canaria de Antropologia, 2009. n. 2.

POMIAN, Krzysztof. Colecção. In: IMPRENSA NACIONAL. Enciclopédia

Einaudi. Lisboa: Imprensa Nacional, 1984. v. 1, p. 51-86. 


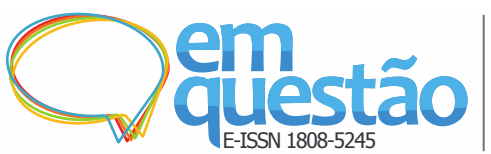

O Museu do Balseiro de Itá como patrimônio cultural de Santa Catarina

Ana Maria Dalla Zen, Lilian Santos da Silva Fontanari

PREFEITURA MUNICIPAL DE ITÁ. Prefeitura conclui restauração das Torres da Igreja submersa. Disponível em: http://ita.sc.gov.br/noticias/1/697prefeitura-conclui-restauracao-das-torres-da-igreja-submersa. Acesso em: fev de 2019.

QUEROLL, Lorena Sacho; SANCHO, Emanuel. Sujeitos do patrimônio: os novos horizontes da museologia social em São Brás de Alportel. E-cadernos CES, São Brás de Alportel, n. 21, p. 89-112, 2014.

RENK, Arlene; SAVOLDI, Adiles. A comida e gênero num contexto de etnicização. SIMPÓSIO FAZENDO GÊNERO, 8., Florianópolis. Anais [...]. Florianópolis: UFSC, 2008. p. 1-6. Tema: Corpo, violência e poder.

RIVIERE, Georges Henri. Seminario regional de la Unesco sobre la función educativa de los museos. [S.l.]: UNESCO, 1958.

SILVEIRA, Leandro. Pedra Fundamental: praça do centro. In: AMORIM, Gabriela de. O que conhecer em Itá-SC? Blog minhas memórias, Itá, 1 jul. 2014.

SOARES, Bruno Brulon.; SCHEINER, Tereza. Cristina. Moletta. A ascensão dos museus comunitários e os patrimônios 'comuns': um ensaio sobre a casa. In: ENCONTRO NACIONAL DE PESQUISA EM CIÊNCIA DA INFORMAÇÃO, 10., 2009, João Pessoa. Anais [...]. João Pessoa: ENANCIB, 2009. p. 1-21.

SUHRE, Mara. Itá: ontem, hoje e amanhã. [S. l.: s. n.], 2016. No prelo.

VARINE, Hugues de; PRIOSTI, Odalice. O novo museu das gentes brasileiras: criação, reconhecimento e sustentabilidade dos processos museológicos comunitários. Cadernos de Museologia, Lisboa, v. 28, n. 28, p. 57-70, 2007.

VARINE, Hugues de. As raízes do futuro: o patrimônio a serviço do desenvolvimento local. Porto Alegre: Medianiz, 2012.

\title{
The Balseiro's Museum as a cultural patrimony of Itá, Santa Catarina
}

\begin{abstract}
The aim of this study is to reflect about the senses and uses associated to the preservation of the balseiros practice that acted in 1920's in Itá, Santa Catarina, whose knowledge and doings have been (re)afirmed by the Balseiros' Museum (MB). It is considered that, even though the wood action took a toll on the environment, this skill is part of the regional cultural heritage, due to the production of artifacts, means of transportation and work tools, theoretically fundamented in Social Museology, New Museology and Education for
\end{abstract}




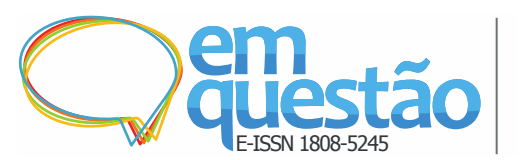

Heritage.The methodology includes documents research of tourist and cultural itinerary that cites the museum, developed by the Secretariat of Tourism, as well as a school project, as reference for assembling a replica of a ferry made by students of the Valentim Bernardi Municipal School. The results of this experience are analysed as educational action for the heritage, from the teachers' and participate students' narratives, gathered at their meeting with the piece displayed at the museum. The connection between material immaterial cultural heritage is discussed as well as preservation and identity, in order to understand how they take part in the educational process. Actions to recapture and preserve the cultural heritage of the shavers in the educational network and how the these have been negotiated and associated to the local history are problematized. It concludes that the experience is useful as a strategy to resgate the memories and the educational heritage, through the appropriation of elements of colonizer's culture.

Keywords: Social Museology. Educational actions in museums. Immaterial cultural heritage. Museu do Balseiro de Itá. Tourism.

Recebido: $24 / 08 / 2018$

Aceito: 15/03/2019

${ }^{1}$ As diárias nos dois hotéis giram em torno de 300 reais, aproximadamente.

${ }^{2}$ Oba, viva veio a enchente o Uruguai transbordou vai dar serviço prá gente. Vou soltar minha balsa no rio, vou rever maravilhas que ninguém descobriu. Se chegar ao Salto Grande me despeço deste mundo, rezo a Deus e a São Miguel e solto a balsa lá no fundo. Quem se escapa deste golpe, chega salvo na Argentina. Só duvido que se escape do olhar das correntinas (MAICÁ, 1978).

3 Professora responsável pela concepção e realização do Projeto Itá, ontem hoje e amanhã. 